\title{
Reflections on a hospital information committee support project in a rural hospital in South Africa
}

\author{
Mc Neill ${ }^{1}$, Laura Mary Campbell ${ }^{2}$, CP. Blanchard ${ }^{1}$ \\ 1. Centre for Rural Health, University of KwaZulu-Natal, South Africa. 2. School of Education, Edgewood Campus, \\ University of KwaZulu-Natal, South Africa.
}

Correspondence: Campbell, LM. Address: School of Education, Edgewood Campus, University of KwaZulu-Natal, South Africa. Email: laura@hss.co.za.

Received: January 9, 2013

DOI : $10.5430 /$ jha.v2n4p100
Accepted: May 23, $2013 \quad$ Online Published: July 4, 2013

URL: http://dx.doi.org/10.5430/jha.v2n4p100

\section{Abstract}

Background: This paper presents an overview of support offered to a hospital information committee by a Hospital Information Committee Support Project (HICSP) in a rural area of South Africa. A specific focus is on the support required at various stages of the project, which was underpinned by Change Theory: any change in practice should be an on-going, phased process (pre-contemplation, contemplation and action). Additionally, change must be seen as having some benefit.

Methods: A cross-sectional, mixed-methods evaluation was conducted to determine whether the project had met its aims and to explore participants' experiences. Quantitative data included: number of meetings held, number of workshops held to develop templates, number of templates developed and in use, and number of action plans developed and implemented. Qualitative data included participants` views of the HICSP. In relation to Change Theory, data was analysed to summarise the type of support required during various stages of the HICSP.

Results: Quantitative data revealed that the aims of the HICSP were met. In accordance with Change Theory, support must be regularly provided and must be on-going over a relatively prolonged period of time. Qualitative data illustrated that, generally, the support given was considered to be appropriate and participants continued to collect, analyse, use and monitor data and information on completion of the HICSP.

Discussion and conclusions: The need for the strategic use of data at a local level to inform decision making and action is unquestionable. The study demonstrates that in an isolated, rural area an information committee can, in accordance with the stages of Change Theory, be supported and empowered so that hospital and nursing managers can confidently use data in a way that is locally meaningful and responsive.

\section{Key words}

Hospital information committee, Nursing managers, Change theory, Data interpretation, Local data use

\section{Introduction}

In general, there is agreement that robust integrated information systems form the foundations for building successful healthcare delivery systems. Accurate and up-to-date information is important in making health-related decisions ${ }^{[1]}$. 
Despite this recognition, meaningful information may not be readily available to those who collect data at a local level, and healthcare workers may, thus, be unable to formulate strategic plans based on accurate, up-to-date, local information.

The World Health Organization ${ }^{[2]}$ recognised the value of health information systems and lists information as one of five key building blocks in any health system. While each of the five building blocks of the WHO framework is seen as important, quality and timely data from health information systems is recognised to underpin and inform decision making in all areas of a health system ${ }^{[3]}$. According to WHO, health information system performance should be measured not only on the quality of data produced, but on evidence of the continued use of data to improve health system performance, to respond to emergent threats, and to improve health ${ }^{[2]}$.

A report by MEASURE Evaluation explored possibilities to strengthen the use of data around decision making in health systems ${ }^{[4]}$. According to this report, data too often sit in reports on shelves, or in databases, and are not sufficiently used in programme development and improvement, policy development, strategic planning, or advocacy. Health data and information lack value unless they are used to inform decisions ${ }^{[5]}$.

In order to facilitate the use of routine data and information for decision making, time and resources must be allocated to data extraction, analysis and presentation ${ }^{[6]}$. The examination of data can also be facilitated through reporting the data in an easy-to-understand way ${ }^{[6]}$. International literature advocates that a 'bolt and key approach' to information management, where information is captured, stored away and not accessible to clinicians is not consistent with an environment of smart use of data and information ${ }^{[6]}$. Board and Watson ${ }^{[7]}$ stated that we should be using what we gather and harnessing information for improved care. The importance of local accessibility of data is well supported by literature; for example, hospital mortality information can be used to alert managers to the need for further investigation and action at an institutional level ${ }^{[8]}$.

\section{The South African context}

Recognition of the importance of health information systems is reflected in South Africa when, in 1996/7, the District Health Management Information System (DHMIS) was established as a routine system for tracking health service delivery in the public health sector ${ }^{[9]}$. The DHMIS plays a pivotal role in the collection, capturing, storage, analysis and reporting of routine data. Data is collected at service-level, for example by programme managers (such as the tuberculosis programme manager), nurses at clinics and nurses working on hospital wards. A Facility Information Officer at each hospital collates the data and sends it to a District Office. At the District Office, data is collated from all programmes, clinics and hospitals in that district and forwarded to a National Data Information System, where analysis occurs. There are challenges in this process of collection, collation and analysis; there is little involvement of local managers of specific programmes (such as tuberculosis and primary health care programmes), clinics and hospitals in making local sense of data collected ${ }^{[9]}$.

The DHMIS policy guidelines of 2011 indicate that an analysis of data should be disseminated to all tiers of the health system and states that: (a) data shall be used at the point of collection, prior to being sent up to the next level of the health system and (b) managers shall ensure that data collected by their respective facilities are reviewed during their monthly management meetings, and that remedial interventions are implemented to improve service delivery where the data shows inadequate performance ${ }^{[9]}$.

Information management is also addressed in the National Core Standards for Health Establishments in South Africa Revised 2010. The National Core Standards state that a healthcare establishment must submit clinical, managerial and administrative information as required, but also that management should use information to inform their own decision making and planning ${ }^{[10]}$. 
Despite the policy guidelines, anecdotal reports indicate that public health institutions in South Africa rarely have opportunities to critically review routine data. A vast amount of routine data is collected on a monthly basis, and sent off to the District Health Office for reporting to the Provincial and National Departments of Health, but little or no time is set aside to review the local outcomes of the hospital or community-based programmes.

\section{The HICSP}

The HICSP was initiated on a premise that a forum needs to be developed, implemented and supported at which hospital, nursing and programme managers and clinic staff can interact in a non-threatening environment, can interrogate the data that is being collected, and can formulate action plans based on their reflections. The HICSP team comprised consultants from the Centre of Rural Health at the University of KwaZulu-Natal and included an expert in human resources, a Family Medical Practitioner and a research psychologist. The Human Resource expert addressed issues related to personnel such as absenteeism. The Family Medical Practitioner and research psychologist addressed issues such as overcrowding in the hospital outpatient department and poor patient uptake of programmes, such as the cervical screening programme. The agenda of the HICSP and timing of meetings was determined collaboratively by the HICSP and the existing rudimentary, informal Hospital Information Committee (HIC). The value of HICs in using data to implement local change is noted in literature ${ }^{[11]}$.

The paper presents data from an evaluation of the HICSP - a project that primarily aimed to support translation of routinely collected data to meaningful information by those who collect the data. An initial aim of the HICSP was to establish a formal forum (a hospital information committee [HIC]), to meet monthly, and at which members could reflect on routinely collected data and formulate and implement action plans based on their reflections. Details of these action plans will not be covered within this paper and will be discussed in a subsequent article.

The underlying philosophy of the HICSP was based on Change Theory ${ }^{[12]}$ where the basic aim was to change healthcare workers use of their data to make it more meaningful to them. Any change is rarely a discrete, single event. The HICSP team took cognisance that change occurs gradually, with a person moving from being uninterested, unaware, or unwilling to make a change (pre-contemplation), to considering change (contemplation), to deciding and making and maintaining change (action and maintenance). Genuine, determined action is taken when a person sees a benefit to their actions and change is maintained over time if the action proves to be beneficial. The HICSP team, using their experiences of the process, reframed the stages of Change Theory in terms of support required to: a) stage 1- recognise that a problem exists regarding use of data, b) stage 2- gain ownership of data, and c) stage 3- act on data and monitor on-going action. Literature supports that adopting Change Theory can be useful in promoting the introduction of required change, the building of organisational capacity and fostering programme sustainability (including healthcare delivery) ${ }^{[13-15]}$.

\section{The specific objectives of the HICSP were:}

a. To establish a formal HIC at a rural district hospital

b. To develop, implement and monitor, in conjunction with key role players, standardised templates for the collection and presentation of data.

\section{Quantitative outputs measured included:}
a. Number of facilitated HIC meetings held
b. Number of workshops held to develop data collection and presentation templates
c. Numbers of data presentation templates produced and in use
d. Numbers of action plans developed
e. Percentage of actions plans implemented, with a target of $80 \%$ implemented action plans. 
In addition, as described below, qualitative data was collected to describe participants' experience of the HICSP. Data was analysed in relation to reframed Change Theory.

\section{Methods}

\subsection{Study setting}

The study site was a rural district-level hospital in KwaZulu-Natal, South Africa.

\subsection{Study design}

The design was a cross-sectional, mixed-methods evaluation.

\subsection{Sample}

The sample included all personnel who present data on a monthly basis at the HIC meetings. Potential participants were mostly nurses: the programme managers for (1) Maternal Child and Women's Health, (2) HIV and ARVs, (3) TB, and (4) Mental Health. The three Primary Health Care (PHC) supervisors and the Chief Executive Officer (CEO) of the hospital were also targeted. The total number of participants available was eight and all agreed to participate in the study.

\subsection{Data collection}

For the collection of quantitative data, records were kept by the HICSP team using Excel. Data recorded included: number of meetings held, number of workshops held to develop templates, number of templates developed and in use, number of action plans developed, and number of action plans implemented. Qualitative data was collected by an independent evaluation team from the Centre for Rural Health at the University of KwaZulu-Natal. Data was collected by conducting in-depth interviews with participants. Written informed consent was obtained from study participants before conducting the interviews. It was emphasized that participation was voluntary and that participants could withdraw at any time. The anonymity of participants was guaranteed, and they were assured that their information would be treated confidentially. A semi-structured questionnaire was used for the in-depth interviews. Interviews were audio-recorded with the permission of the respondents and transcribed verbatim.

\subsection{Data analysis}

Quantitative data was analysed descriptively. For the qualitative data, thematic analysis was used as the primary analytic strategy. Thematic analysis means that material is searched for themes that emerge as being important to the description of the phenomenon, rather than being pre-decided by the researcher ${ }^{[16]}$. This process involves identification of themes through careful reading and re-reading of the data. Transcripts were coded by two researchers from the evaluation team. After reading a transcript, the researchers collaboratively developed a codebook of themes around the main topics. The second transcript was then reviewed to add additional topic areas and themes that emerged. This process was then repeated with each remaining transcript to arrive at a final coding scheme. Finally, emergent themes were summarised in relation to the stages of reframed Change Theory.

Data were entered into QSR International's NVivo 8 qualitative data analysis software and coded independently by the two researchers per the coding scheme. The researchers met regularly throughout the process to discuss coding, modifying the coding scheme and maintaining fidelity to the coding scheme, until consensus was reached.

\subsection{Scientific rigor}

The evaluation team employed certain strategies to ensure trustworthiness of the data. The basic question addressed by the notion of trustworthiness is: How can an inquirer persuade his or her audiences that the research findings of an inquiry are 
worth paying attention to?" [17]. Literature describes three criteria for ensuring trustworthiness, namely credibility, transferability and dependability ${ }^{[17]}$.

Attention was given to credibility (checking the true value of findings) by means of independent coding. Transferability was established by thoroughly describing the research context and the assumptions that were central to the research. The person who wishes to "transfer" the results to a different context is then responsible for making the judgment of how sensible the transfer is. The researcher also needs to provide sufficient information that can then be used by the reader to determine whether the findings are applicable to the new situation ${ }^{[17]}$. To this end, the researchers have included a number of quotes from the verbatim transcriptions. Dependability was maintained through keeping of the raw material, giving a full description of the research method, and applying the same procedure throughout.

\subsection{Ethics}

Ethical review was conducted by the Human and Social Sciences Ethics Committee of the University of KwaZulu-Natal (reference number: hss/1347/010).

\section{Results}

Results are presented as quantitative and qualitative and an overarching aim is to illustrate the stages of support (in relation to reframed Change Theory) required during the HICSP.

\subsection{Quantitative results}

Quantitative results are presented as process indicators: number of monthly meetings held; number of workshops held to develop data presentation templates; number of data presentation templates produced and in use; number of action plans developed; and percentage of action plans completed.

The number of monthly meetings held over the two year period (June 2009-June 2011) was 17. Several meetings were missed as a result of members of the HIC having to attend other meetings. This illustrates the complexity of holding monthly meetings in rural South Africa.

The number of workshops held to develop templates was seven and this illustrates that time was required for participants to understand the aim of the HIC (the agenda and timing of the HICSP was set jointly by the facilitators and the HIC), to recognise and problematise that there is no local use of routinely collected data, to take ownership of the data and make decisions around what data is locally relevant. This process was considered vital in relation to the first two stages of reframed Change Theory.

The number of standardised templates developed and in use by the end of the project was six.

The number of action plans developed as outputs of the monthly meetings, based on reflecting on the routine data, was 71 .

Close management of the action plans through participants having to take accountability and report back on their progress at the monthly meetings resulted in all 71 plans being fully implemented (details of these actions will be described in a subsequent article). A target of completing $80 \%$ of formulated action plans was set for the HICSP, and the target was, therefore, met and exceeded.

\subsection{Qualitative results}

The major themes that emerged from the qualitative data in relation to the three stages of reframed Change Theory are discussed below, and enforced with quotations from the participants. Qualitative data was themed according to: a) stage 1- 
recognising and articulating the problem around data collection, b) stage 2- taking ownership of data, and c) stage 3- acting on and monitoring data.

\section{a) Stage 1- recognising and articulating the problem (reframed Change Theory, stage 1)}

All participants stated that they did not reflect at all on routinely collected data prior to the HICSP. One of the participants articulated that the specific problem was that there was no system in place to ensure that the data collected by participants was used by participants. This point is illustrated in the following quotation:

There was no system of making use of the information.

Although there was little qualitative data from this study to highlight the reframed Change Theory first stage of recognising and articulating a problem, the researchers are of the opinion that this phase is vital as participants would be unwilling to change if they do not perceive that a problem exists. Data illustrates that, prior to the HICSP, participants perceived no personal benefit to collecting data.

\section{b) Stage 2- participants taking ownership of data (reframed Change Theory, stage 2)}

Participants illustrated that they took ownership of data collection by, for example, realising of the value of having accurate data.

They have highlighted to us the importance of writing the correct information. You must not just write anything; you must write the correct thing and send the correct information.

Ownership was demonstrated when participants reflected on why they collected data and related data collection to their own performance.

Data collection, it is basically to review the programmes (such as the tuberculosis programme), the performance; how we are improving.

We measure where we are at that point in time. We measure where we have been and where we are going. As you look at the data monthly you can see, okay, I am going backwards there or going forward there; I want to reach higher next time.

The above quotations illustrate that participants began to see a personal benefit to collecting of the data. Ownership was also illustrated as participants mentioned that reviewing data allows them to take personal accountability for data. They said they needed to "identify the gaps" in data and "when you have all the information you can make an informed decision, so that the programmes can run smoothly".

One respondent felt that the reason for having information was "to improve the standard of the care we are giving our clients." Other quotations are included to illustrate that the participants, and other people they presented their templates to, developed some sense of ownership of the data.

When looking at the information with everyone there - the operational managers, the management and the people who are hands on - you are able to interrogate the information. You actually learn from the information that you get.

And the people who are actually doing the work they learn how to do the work understandably, knowing where they are going. 
With my presentation they now know the problems or the challenges that we are facing, as well as the achievements in our programme.

You get to know how to present data. At first you do not have confidence, but with the knowledge of how the calculations are done, how to present, how to make your presentation attractive and informative, that gives you the power. You own your data.... Actually the district has learnt from my presentations; they have seen me present and they understand it.

You tend to be more confident when you present something that you know. It's very good. If someone asks questions, you know how to answer back.

The above quotations illustrate that data collection had become useful to participants at a personal level.

\section{C) Stage 3- acting on and monitoring data and information (reframed Change Theory, stage 3)}

Participants reflected on the HICSP support and noted that using data appropriately enabled them to act on and monitor information at their local level. This point is illustrated by the following quotations:

The information is looked at, the trends are looked at, and then recommendations are made and action plans are made. At the start of each meeting people present what action plans came from the previous meeting and they review what they have done and what they have found out. I have gained a lot of knowledge. I can determine targets using the catchment population. Now I can see that this month we have done this, and why they have gone up or down, and I can explain.

It was an eye opener for me. You can see if you are doing well or not doing well using the monthly and yearly targets.

It was very useful; we have our own target now. Previously we did not have our own targets for each clinic for initiation. We knew our testing rate must be $95 \%$, our CD4 taken must be 100\%, but we did not know how many we must initiate in a year.

Action plans were formulated based on targets not being reached for indicators. And one would notice that there is a gap and decide what is the next step or the way forward.

A number of participants mentioned specific successes achieved through the action plans that were developed and implemented.

We were not doing well in cervical cancer screenings, but now the numbers are up. We set a target for each clinic.

One participant mentioned an action plan to address the very high numbers presenting to the outpatient department (OPD) at the hospital. Physicians at this hospital had stopped visiting the clinics attached to the hospital and numbers of patients attending the OPD had increased consequently. The action plan involved examining the utilisation rates of each of the clinics and then rostering doctors to visit the clinics, with more visits scheduled to the very busy clinics. This resulted in a marked impact on both the outpatient department's headcount and the clinic headcounts:

We took doctors to the clinics so that the patients remain where they are and we take the services to the patients. That changed the picture overnight - less out-patient department count and a very high Primary Health Care (participant refers to patients who visit clinics) headcount, just because of that change. 
The above quotations illustrate that participants have taken ownership of their data and participants have progressed to seeing value in acting on information and monitoring that action. The quotations additionally highlight that participants see a broader and very positive value to using their information appropriately.

\section{d) General comments on the HICP}

Most participants expressed the value of the HICP in promoting and monitoring action.

It was a great experience. I gained a lot; I learnt a lot. I did not know that I would come out knowing such a lot. It was a great experience for me.

Participants also commented that the workshops held for template development were "very useful". With regard to the templates themselves, participants valued the fact that they have honed in on vital or "core indicators" and most stated that the templates were user-friendly.

Just look at the layout (of the template); it's totally different. If you can compare it to the data that was presented say last year June or July, it was in a table form then, with numbers. It is now in a graph form and it's very easy to understand, straight to the point; you gain a lot. Everyone can understand them (the templates) at the presentation.

Most participants stated that they will continue to use their respective templates after the HICSP ends.

Yes, I will continue to use it (the template). You can even ask the other districts to use it (the template); it was so useful to us. You can ask others to perform as we are performing.

Most stated that the information committee meetings should and will continue. The Hospital and Programme Managers were identified by participants as being the most appropriate people to coordinate the continuation of regular HIC meetings.

We are now proud, we can present everything. We have learnt how to do action plans and how to conduct the meeting itself.

We will continue with the way we have been doing it. It has given us the light.

It is very important to carry on with it. If you don't carry on with it you put all that hard work to nothing.

\section{Discussion}

Findings from this study illustrate that the HICSP provided a practical methodology for the interpretation, presentation, use and monitoring of data routinely collected by members of the HIC. The support offered by the HICSP included: regular facilitated meetings, co-development of standardised data presentation templates, co-development of action plans and monitoring of whether action plans were implemented. The overall success of the HICSP is reflected in the meeting of the objectives of the HICSP: a HIC was instituted, templates were produced and were still in use on completion of the HICSP, and action plans were developed and fully implemented. Participants are now using the data they gathered as a strategic resource to inform decision making ${ }^{[6]}$ and are translating decisions based on information into action. The desired outcome of this strategic use of information should be improved quality of care ${ }^{[7]}$. The evaluation of the HICSP did not, however, assess quality of care or the impact of the implementation of action plans on patient outcomes and this requires further evaluation. If action plans are appropriate and are successfully implemented, then the HICSP has the potential to strengthen programme management and, ultimately, improve patient outcomes. 
Supporting a HICSP cannot be seen as a once-off, easy venture and the three stages of the reframed Change Theory may provide a framework for the planning, implementing and monitoring of future HICSPs in a rural African setting.

Participants particularly valued the initial stages of co-developing data presentation templates (stage 1 and 2 reframed Change Theory). The importance of retailoring the format in which data is presented is emphasised by Nutley ${ }^{[4]}$, who states that data users in a health system have different information needs and need information at different levels of detail and complexity. Ensuring that data are understood by potential users requires that data become personally meaningful, synthesised and disseminated in formats that are targeted to the individual and organisational contexts in which they are intended to be used ${ }^{[4]}$. Findings from this study support that data was personally meaningful, synthesised and disseminated by means co-developed by the participants themselves. Thus data and information were directly targeted at the members of the HIC and the programmes and organisation they represent.

Participants also mentioned the benefit of honing in on a set of core indicators for their respective programmes. To facilitate data use, focus needs to be placed on what stakeholders need to know to effectively run health programmes, instead of what data are available to them ${ }^{[4]}$. By focusing on the practical questions data users have about their programmes and the upcoming decisions they have to make, it is possible to hone in on the specific data that will inform relevant questions and decision making processes ${ }^{[18-20]}$. As Nutley ${ }^{[4]}$ states, it is important for the data user to recognise what they 'need to know' rather than what is the 'nice to know'.

Raw data are seldom useful for decision making and usually must be transformed into information that is usable and that relates to the issue being addressed ${ }^{[5]}$. For example, it is not enough to know how many clients used services; comparison against a target or previous performance may be needed ${ }^{[5]}$. Participants in the current project reported the value of being able to monitor programme performance based on context-specific targets for each indicator. Not reaching a target pointed participants towards avenues for further action. South Africa's DHMIS Policy ${ }^{[9]}$ stresses the importance of setting targets. The policy states that each District Manager shall be responsible for ensuring that provincial targets are adapted for their district.

The act of presenting data is one of the core competencies of data use ${ }^{[4]}$. The HICSP participants, as a result of userfriendly presentation templates, appeared to feel more confident in presenting data to other people and in answering questions about their respective programmes.

Stage 3 of the reframed Change Theory is reflected in the action taken by participants in response to their synthesis and analysis of data. With regard to the sustainability of the project, all participants reported they would continue to use the templates, take action based on analysed data and monitor the effect of action. They also would continue to hold monthly HIC meetings.

\section{Limitations of the study}

Although this research shows promising results, it is important to note the limitations of the study. First, no evaluation of the impact of implemented action plans was carried out. The study would be strengthened if a positive association could be found between action plans implemented and improved patient care. Second, the study focused on one rural district hospital with a resulting small number of participants, thus raising questions around transferability. It is recommended that the study be repeated with other participants in other sites. It is also necessary to analyse the organisational and behavioral factors that might have played a role in the success of the project at this study site, as this will inform possible rollout to other sites. It is possible that, in the in-depth interviews, participants said what the felt the researchers wanted to hear (researcher bias), although the interviews were carried out by evaluators who were not part of the HICSP. 


\section{Conclusion}

The need for the strategic use of data at a local level to inform-decision making and action is unquestionable. The current study illustrated that change cannot be viewed as a once-off event and support needs to be on-going and regular. The reframed Change Theory stages employed in this project may prove a useful basis for others who wish to develop and implement a HICSP, as the same staged approach could be used. This study indicates that changes around data collection and analysis took time, and change only occurred when participants saw problems in the existing system and recognised the benefit in changing.

The success of the HICSP is reflected in the meeting of its aims. In particular, all action plans were fully implemented (this paper does not aim to provide details of how each action plan was implemented). A need to evaluate the impact of action plans on patient outcomes is identified.

The qualitative data demonstrated the value of participant empowerment by processes such as co-developing data collection and presentation templates and presenting data in a user-friendly manner. The need to hone in on core indicators and take account of context specific targets is noted. The HICSP was valued by participants, who expressed increased confidence in translating data to information, and in making use of information.

\section{Acknowledgements}

The authors would like to thank the following who were involved in the evaluation of the HICP: Christiane Horwood, Lyn Haskins, Merridy Grant, and Reshma Subbaye. The HICP was funded by the Atlantic Philanthropies.

\section{References}

[1] Kumar, V. Impact of health information systems on organizational health communication and behavior. The Internet Journal of Allied Health Sciences and Practice. 2011; 9(2): 1-5.

[2] World Health Organization. Everybody's business: Strengthening health systems to improve health outcomes, WHO's framework for action. Geneva: World Health Organization. 2007.

[3] AbouZahr, C., \& Boerma, T. Health information systems: the foundations of public health. Bulletin of the World Health Organization. 2005; 83(8): 578-83.

[4] Nutley, T. Improving data use in decision making: An intervention to strengthen health systems. 2012 [Internet]. Available from: http//ww.hst.org.za/publications/improving-data-use-decision-making-intervention-strengthen-health-systems.

[5] Foreit, K., Moreland, S., \& LaFond, A. Data demand and information use in the health sector: A conceptual framework. 2006 [Internet]. Available from: http://www.cpc.unc.edu/measure/publications/ms-06-16a (Retrieved 12 December 2012).

[6] Lloyd, S., Collie, J., McInnes, A., King, K., Lollback, A., \& Garland, A. Smart use of data, information and communication: The INFORM-ed Best Local Practice Project--Grafton Base Hospital. Health Information Management Journal. 2011; 40(3): 26-30. PMid:22006434

[7] Board, N., \& Watson, D. Using what we gather - harnessing information for improved care. Medical Journal of Australia. 2010; 193(8): S93-4. PMid:20955140

[8] Ben-Tovim, D.I., Pointer, S.C., Woodman, R, Hakendorf, P.H., \& Harrison, J.E. Routine use of administrative data for safety and quality purposes - hospital mortality. Medical Journal of Australia. 2010; 193(8): S100-3. PMid:20955135

[9] Department of Health. District Health Management Information System (DHMIS) Policy2011. 2011 [Internet]. Available from: http://www.doh.gov.za/docs/policy/2012/dhmis.pdf (Retrieved 11 December 2012).

[10] National Department of Health. National Core Standards for Health Establishments in South Africa: Abridged version. Tshwane: South African Department of Health. 2011.

[11] Selbmann, H.K. Quality assurance and medical information processing. Acta Hospitalia. 1991; 31(2): 5-10. PMid:10111909

[12] Prochaska, J.O., \& DiClemente, C. C. Transtheoretical therapy: Toward a more integrative model of change. Psychotherapy: Theory, Research \& Practice. 1982; 19(3): 276-288. http://dx.doi.org/10.1037/h0088437

[13] Eccles, M., Grimshaw, J., Walker, A., Johnston, M., \& Pitts, N. Changing the behavior of healthcare professionals: the use of theory in promoting the uptake of research findings. Journal of Clinical Epidemiology. 2005; 58(2): 107-112. PMid:15680740 
[14] Hunter, D. Using a theory of change approach to build organizational strength, capacity and sustainability with not-for-profit organizations in the human services sector. Evaluation and Program Planning. 2006; 29 (2): 193-200. http://dx.doi.org/10.1016/j.evalprogplan.2005.10.003

[15] Weiner, B. A theory of organizational readiness for change. Implementation Science. 2009; 4: 67. PMid:19840381 http://dx.doi.org/10.1186/1748-5908-4-67

[16] Daly, J., Kellehear, A., \& Glicksman, M. The public health researcher: A methodological approach. Melbourne, Australia: Oxford University Press. 1997.

[17] Lincoln, Y., \& Guba, E. Naturalistic inquiry. New York: Sage. 1985.

[18] Devadason, D.J., \& Lingam, P.P. A methodology for the identification of information needs of users. IFLA Journal. 1997; 23(41): 41-51. http://dx.doi.org/10.1177/034003529702300109

[19] Patton, M. Utilization-focused evaluation. 4th ed. Thousand Oaks, CA: SAGE Publications, Inc. 2008.

[20] Koon, A., Nambiar, D., \& Rao, D.R. Embedding of research in decision-making processes. 2012 [Internet]. Available from: http://www.who.int/alliancehpsr_backgroundpaperembeddingresearch.pdf (Retrieved 3 January 2013). 